\title{
A Native American Community with a 7\% Cesarean Delivery Rate: Does Case Mix, Ethnicity, or Labor Management Explain the Low Rate?
}

\section{Lawrence Leeman, $M D, M P H^{1}$ \\ Rebecca Leeman, CNM, MSN ${ }^{2}$}

'Departments of Family and Community Medicine and Obstetrics and Gynecology, University of New Mexico School of Medicine, Albuquerque, NM

${ }^{2}$ Women's Specialists of New Mexico, Albuquerque, NM
Conflicts of interest: None reported

\section{CORRESPONDING AUTHOR}

Lawrence Leeman, MD, MPH

University of New Mexico Family Practice 3rd Floor

2400 Tucker NE

Albuquerque, NM 87131

lleeman@salud.unm.edu

\begin{abstract}
PURPOSE Cesarean delivery rates vary widely across populations. Studying communities with low rates of cesarean delivery may identify practices that can lower the cesarean rate.

METHODS A population-based historical cohort study included all pregnant women ( $\mathrm{N}=1132$ ) from 1992 through 1996 in a predominantly Native American region of northwestern New Mexico known to have a high prevalence of gestational diabetes and preeclampsia. The outcomes studied included delivery type (eg, cesarean, operative vaginal, spontaneous vaginal), indication for cesarean delivery, presence of obstetrical risk factors, and use of labor induction or augmentation.
\end{abstract}

RESULTS The cesarean delivery rate of the study group (7.3\%) was only $35 \%$ of the 1996 US rate of $20.7 \%$. Among study participants, the relative risk of a primary cesarean delivery for dystocia was $0.22(95 \% \mathrm{Cl}, 0.14,0.35)$. Trial of labor after cesarean delivery was attempted by $93 \%$ of study participants compared with $42 \%$ of women nationwide in 1994 . The cesarean delivery rates for women with diabetes in pregnancy $(11.5 \%$ versus $35.4 \%)$ and preeclampsia $(14.8 \%$ versus $37.4 \%$ ) were significantly lower than nationwide rates. Case-mix analysis comparison with a standardized population and comparison of standard (ie, term, singleton, vertex) primiparous women demonstrate that the low rate of cesarean delivery was not because of a lower prevalence of risk factors.

CONCLUSIONS The community's low rate of cesarean delivery is primarily the result of a decreased use of cesarean delivery for labor dystocia and an almost universal acceptance of trial of labor after cesarean delivery. Cultural attitudes toward childbirth, design of the perinatal system, and genetic factors also may explain the low rate of cesarean delivery.

Ann Fam Med 2003;1:36-43. DOI: 10.1370/afm.8

\section{INTRODUCTION}

he desired rate of cesarean delivery has been the subject of much
controversy because the US rate rose from $4.5 \%$ in 1970 to a peak
of $24.7 \%$ in $1988 .{ }^{1}$ After declining from 1989 to 1996 , the cesarean delivery rate increased from $20.8 \%$ in 1997 to $24.4 \%$ in $2001 .^{2,3}$ Comparing US perinatal statistics with those of countries with lower increases in cesarean delivery rates during the same period suggests that the increase has not significantly reduced rates of neonatal morbidity and mortality. ${ }^{4,5}$ The Healthy People 2000 goal to decrease the total cesarean delivery rate to $15 \%$ was criticized as promoting an unsafe increase in vaginal births after cesarean delivery and operative vaginal deliveries. ${ }^{6,7}$ Narrower in 
scope, the Healthy People 2010 goal aims to reduce the primary cesarean rate to $15 \%$ in low-risk women with a term, singleton vertex presentation. ${ }^{8}$

The increase in cesarean deliveries has been attributed to multiple factors, including continuous electronic fetal monitoring, ${ }^{9,10}$ a lower obstetrical threshold for cesarean delivery because of decreased maternal surgical morbidity, medicolegal concerns, ${ }^{11-13}$ increased use of labor induction, ${ }^{14}$ and decreased use of operative vaginal ${ }^{15}$ and vaginal breech delivery. ${ }^{16}$ Cesarean delivery rates are known to vary widely among different population groups, with known risk factors including age ${ }_{,}{ }^{17-20}$ parity ${ }_{1}^{18}$ weight,${ }^{17}$ socioeconomic status, ${ }^{21}$ ethnicity, ${ }_{1}^{22,23}$ and other obstetrical risk factors. Studying communities with low rates of cesarean delivery despite high rates of obstetrical risk factors may help to identify practices that lower the cesarean delivery rate. We studied all pregnancies from 1992 through 1996 in the communities served by Zuni-Ramah Hospital to identify factors associated with the low cesarean delivery rate of $7.3 \%$ in this predominantly Native American population. ${ }^{24}$

\section{METHODS}

Using a population-based historical cohort study design, we examined all pregnancy outcomes beyond 20 weeks of gestation in the Zuni Pueblo and Ramah Navajo communities of northwestern New Mexico from 1992 through 1996. The perinatal services were based at the Zuni-Ramah Hospital, a 37-bed community hospital with family physicians and a nurse-midwife providing obstetrical services without onsite surgical facilities.

Women who required a cesarean delivery, pharmacologic labor induction or augmentation and those who were categorized as high risk by screening criteria were transferred to the Gallup Indian Medical Center (GIMC), 35 miles away in Gallup, NM, or to other medical facilities with operative capabilities. The risk criteria mandating transfer included previous cesarean delivery, malpresentations, multiple gestation, intrauterine growth restriction, severe preeclampsia, placenta previa, significant vaginal bleeding, major fetal anomalies, anticipated preterm delivery (less than 36 weeks), or nonreassuring fetal heart tones. Women with gestational or type 2 diabetes in good control could deliver at Zuni-Ramah Hospital unless they had end organ damage or known macrosomia. The integrated perinatal system and quality assurance monitoring have been described previously. ${ }^{24}$

This population-based study included all pregnancy outcomes regardless of the site of delivery. We interviewed perinatal coordinators, public health nurs- es, and pediatric health care providers to obtain information about patients who had received perinatal care outside of the Indian Health Service system. Because of the isolated geographic location and the integration of maternity and pediatric services, it is likely that the study population included all births in the community.

One group of health care professionals provided all prenatal care through the Zuni-Ramah Hospital. The family-physician-run birthing unit had ready access to obstetrician-gynecologist consultants in Gallup and perinatal/neonatal care in Albuquerque. Any woman who was initially admitted in labor to Zuni-Ramah Hospital required consultation and transfer before the initiation of a cesarean delivery. No economic factors affected transfer of care to GIMC, because the physicians were salaried at both institutions. The obstetrician-gynecologist staff at GIMC reviewed all cesarean deliveries monthly to determine appropriateness of care. The inability to offer labor induction or augmentation at Zuni-Ramah Hospital discouraged unnecessary inductions or hospital admission before the onset of active labor. Women with diet-controlled gestational diabetes were permitted to go to 42 weeks before induction, and women whose insulin-dependent diabetes was well controlled were not routinely induced until 40 weeks of gestation. Gestational diabetes was diagnosed using National Diabetes Data Group criteria. ${ }^{25}$ Epidural analgesia was not available at the Zuni-Ramah Hospital and was rarely used at GIMC. All patients receiving prenatal care underwent ultrasonography, usually at 16-18 weeks, to confirm gestational age and to minimize unneeded transfers for preterm labor or post-term pregnancies. Evidence-based obstetrical guidelines supported the maternity care practices that minimized elective induction or cesarean delivery (Table 1).

The Zuni and Navajo tribes are culturally and genetically distinct. Traditional religious beliefs and childbirth customs of the 2 tribes have little in common. The Zuni, like other Pueblo Indians, are descended from the Anasazi people, while the Navajo are linguistically and genetically linked to the Athabascan people in Alaska. The Zuni live in a relatively densely populated village of 9200 persons, located 3 miles from Zuni-Ramah Hospital, while the Ramah Navajo, population of 2000, live in more isolated settlements on a reservation 45 miles from the hospital.

We used a data-collection form to review and abstract prenatal, intrapartum, and newborn records from every birth at Zuni-Ramah Hospital or GIMC. We obtained discharge summaries for all deliveries from tertiary care referral sites. The outcomes measured included delivery type (eg, cesarean, operative 


\begin{tabular}{|c|c|}
\hline Condition & Management \\
\hline Previous cesarean section & $\begin{array}{l}\text { Trial of labor strongly encouraged for women meeting ACOG } \\
\text { criteria (at a hospital with cesarean delivery capability) }\end{array}$ \\
\hline Breech & $\begin{array}{l}\text { All offered external cephalic version at } 37 \text { to } 38 \text { weeks; selective } \\
\text { availability of vaginal breech birth at Gallup Indian Medical } \\
\text { Center }\end{array}$ \\
\hline Postdates & $\begin{array}{l}\text { Nonstress test and amniotic fluid index biweekly starting at } \\
41 \text { weeks; if reassuring, induction deferred until } \geq 42 \text { weeks }\end{array}$ \\
\hline Mild preeclampsia & Induction at 37 to 39 weeks based on Bishop score \\
\hline GDM A1 & $\begin{array}{l}\text { Nonstress test and amniotic fluid index biweekly starting at } \\
40 \text { weeks; if reassuring, induction deferred until } 42 \text { weeks }\end{array}$ \\
\hline $\begin{array}{l}\text { Chronic hypertension, } \\
\text { pregestational diabetes, } \\
\text { and GDM A2 }\end{array}$ & $\begin{array}{l}\text { Induction at } 38 \text { to } 39 \text { weeks depending on Bishop score and } \\
\text { antepartum surveillance }\end{array}$ \\
\hline Elective/social induction & Not done \\
\hline Induction for macrosomia & Not done in women without diabetes \\
\hline $\begin{array}{l}\text { Premature rupture of } \\
\text { membranes at term }\end{array}$ & $\begin{array}{l}\text { Option of expectant management for up to } 72 \text { hours; most } \\
\text { women were induced at } 24 \text { to } 48 \text { hours if not in labor. }\end{array}$ \\
\hline $\begin{array}{l}\text { Group B streptococcus } \\
\text { prophylaxis }\end{array}$ & $\begin{array}{l}\text { The CDC risk-factor-based protocol was used rather than a } \\
\text { screening-based protocol. }\end{array}$ \\
\hline
\end{tabular}

by Lieberman et $\mathrm{al}^{26}$ and recommended by the American College of Obstetricians and Gynecologists (ACOG) Task Force on Cesarean Delivery Rates, ${ }^{27}$ was used to compare the Zuni-Ramah population to a standardized community-based population from Boston.

\section{RESULTS}

A review of the delivery and transfer records of the Zuni Indian Hospital and GIMC obstetrical services demonstrated 1132 births of 1137 infants from 1992 through 1996.

There were 1128 live births because of 9 cases of intrauterine fetal demise. Ninety-four percent of births occurred at Zuni Indian Hospital (64.4\%) or GIMC (29.6\%).

Table 2 describes the demographics

vaginal, spontaneous vaginal), indication for cesarean delivery, use of labor induction or augmentation, delivery site, and perinatal mortality and morbidity. The outcomes for site of delivery and perinatal morbidity and mortality have been published elsewhere. ${ }^{24}$ Births were defined as deliveries of infants at 20 weeks' estimated gestational age or older. Each birth in a multiple gestation was analyzed individually. Approval for the study was granted by the Indian Health Service Institutional Review Board and the Zuni Tribal Council.

We compared the cesarean delivery rates of the Zuni-Ramah population with the 1996 nationwide rates to identify subgroups with specific obstetrical risk factors who had different cesarean delivery rates. Risk factors that were analyzed included parity, age, previous cesarean delivery, diabetes, hypertension, preeclampsia, multiple gestation, fetal presentation, and use of labor induction or augmentation. We compared the indications for cesarean deliveries in ZuniRamah women and 1994 nationwide hospital discharge data to identify specific indications with lower cesarean rates in the Zuni-Ramah population. We also compared the demographics and obstetrical outcomes of the Zuni-Ramah community with the overall New Mexico Native American population with $\chi^{2}$ analysis.

Case-mix adjustment using standardization permits a comparison of cesarean delivery rates between populations with differing demographics and obstetrical risk factors. The adjusted rate is the cesarean delivery rate that would be expected if the study population had the same patient mix as the standardized population. The case-mix adjustment technique, which was developed of the Zuni-Ramah population.

The cesarean delivery rate in the Zuni-Ramah population was significantly lower than the national rate in 1996 for total (7.3\% versus 20.7\%) and primary $(5.3 \%$ versus $14.6 \%)$ cesarean deliveries. ${ }^{28}$ Among women with previous cesarean delivery, trial of labor after cesarean (TOLAC) delivery was attempted in $93 \%(\mathrm{n}=87)$ of pregnancies in the study population, compared with $42 \%$ of women nationwide in $1994 .{ }^{29}$ Of women in the Zuni-Ramah population who attempted TOLAC, $77 \%$ had a vaginal delivery, which was similar to findings from other studies of TOLAC. ${ }^{30-32}$ The study population had lower rates of labor induction, oxytocin augmentation, and operative vaginal delivery, compared with 1996 national rates ${ }^{28}$ (Table 2). Although comparative national statistics are unavailable, the use of episiotomy (7.4\%) and labor analgesia $(31.3 \%)$ in vaginal deliveries is low.

The study population had a greater incidence of preeclampsia (based on 1996 ACOG criteria ${ }^{33}$ ), chronic hypertension, and diabetes than the average obstetrical population in the United States ${ }^{28}$ (Table 2). The study population had a lower incidence of other risk factors compared with the US population, including advanced maternal age $(10.4 \%$ versus $12.2 \%)$, previous cesarean delivery $(7.7 \%$ versus $10.5 \%)$, and multiple gestation $(0.44 \%$ versus $2.74 \%) .{ }^{28}$ The cesarean rate was significantly lower in subgroups with more significant risk factors, including advanced maternal age $(10.1 \%$ versus $27.8 \%$ in the US population), diabetes (11.5\% versus $35.4 \%$ ), and preeclampsia (14.8\% versus $37.4 \%) .{ }^{28}$ Labor induction was associated with an increased 
cesarean delivery rate $(10.8 \%)$ in the Zuni-Ramah population, as demonstrated in other populations. ${ }^{14}$

Standardization by case-mix analysis (Tables 3 and 4) demonstrates that if the Zuni-Ramah obstetrical population were similar to the standardized population $^{26}$ in parity and obstetrical conditions, the cesarean delivery rate would still have been only $11.5 \%$ (95\% CI, 9.9\%-13.1\%). Another technique developed to standardize for parity, presentation, and gestational age is to compare the cesarean delivery rate in a "standard primipara" population that includes only singleton pregnancies of at least 37 weeks' gestation with a vertex presentation. ${ }^{34,35}$ The Zuni-Ramah standard primipara population had a $4.5 \%$ cesarean delivery rate, compared with a $17.9 \%$ rate nationwide in $1996 .{ }^{27}$

We compared indications for primary and repeat cesarean delivery between the Zuni-Ramah and 1994 nationwide populations to determine the relative influ- ence of each indication on the low cesarean rates (Table 5). ${ }^{29}$ The relative risk of a primary cesarean delivery at Zuni-Ramah Hospital was significantly lower than that of the nationwide US population for each of the identified indications. The lowest relative risk was for labor dystocia (0.22), which is the indication for more than $50 \%$ of US cesarean deliveries.

The relative risk of an elective repeat cesarean delivery at Zuni-Ramah Hospital is 0.11 , because only $0.5 \%$ of Zuni-Ramah births are elective repeat cesarean deliveries, compared with $4.66 \%$ of births nationwide. This was primarily because the low rate of primary cesarean deliveries meant that only $10.9 \%$ of multiparous pregnancies occurred in women with previous cesarean deliveries. The high proportion (93\%) of women with a previous cesarean delivery who attempt a trial of labor further decreases the incidence of elective repeat cesarean delivery.

One concern about a low rate of cesarean delivery

\begin{tabular}{|c|c|c|c|c|c|}
\hline & \multirow{2}{*}{$\begin{array}{c}\begin{array}{c}\text { Zuni-Ramah, } \\
1992-1996\end{array} \\
(\mathrm{~N}=1128)^{*} \\
\%\end{array}$} & \multicolumn{2}{|c|}{$\begin{array}{l}\text { United States, } 1996 \\
(\mathrm{~N}=3952767)^{28}\end{array}$} & \multicolumn{2}{|c|}{$\begin{array}{c}\text { New Mexico Native American, } \\
1994(\mathrm{~N}=3645)^{36}\end{array}$} \\
\hline & & $\%$ & P value $^{\dagger}$ & $\%$ & $\mathbf{P}$ value ${ }^{\dagger}$ \\
\hline Age & & & $<.0001$ & & .74 \\
\hline$<20 y$ & 19.7 & 12.9 & & 18.6 & \\
\hline $20-34 y$ & 69.9 & 74.9 & & 70.9 & \\
\hline$\geq 35 y$ & 10.4 & 12.2 & & 10.4 & \\
\hline Parity & & & $<.0001$ & & .10 \\
\hline Nulliparous & 29.7 & 41.0 & & 32.3 & \\
\hline Parous & 70.3 & 59.0 & & 67.7 & \\
\hline Prenatal care & & & $<.0001$ & & $<.0001$ \\
\hline Early (1st trimester) & 43.0 & 81.9 & & 51.8 & \\
\hline Birth weight & & & $<.0001$ & & $<.0001$ \\
\hline$<2500 \mathrm{~g}$ & 5.4 & 7.4 & & 6.4 & \\
\hline$>4000 \mathrm{~g}$ & 4.8 & 10.2 & & 9.6 & \\
\hline Gestational age & & & $<.0001$ & & .01 \\
\hline$<37$ wk & 7.0 & 11.0 & & 7.1 & \\
\hline$>41 w k$ & 4.4 & 8.7 & & 2.6 & \\
\hline \multicolumn{6}{|l|}{ Risk factors } \\
\hline Diabetes & 9.2 & 2.6 & $<.0001$ & 5.6 & $<.0001$ \\
\hline Pregnancy-induced hypertension & 14.5 & 3.6 & $<.0001$ & 5.2 & $<.0001$ \\
\hline Labor management & & & .02 & & .0004 \\
\hline Labor induction & 13.8 & 16.9 & & 11.8 & \\
\hline Labor augmentation & 7.7 & 7.7 & & 11.6 & \\
\hline Operative vaginal delivery & 5.1 & 9.4 & $<.0001$ & 5.2 & .89 \\
\hline Delivery route & & & $<.0001$ & & $<.0001$ \\
\hline Vaginal & 92.6 & 79.3 & & 87.5 & \\
\hline Primary cesarean delivery & 5.3 & 14.6 & & 8.3 & \\
\hline Repeat cesarean delivery & 2.0 & 6.1 & & 4.1 & \\
\hline
\end{tabular}

${ }^{*} N \leq 1128$ for certain categories because of data unavailable from chart review.

$+P$ values for comparison with Zuni-Ramah population. 
Table 3. Case-mix analysis of Cesarean Delivery Rate According to Parity Group and Obstetric-Condition Category for Zuni-Ramah Population

\begin{tabular}{|c|c|c|c|c|}
\hline $\begin{array}{l}\text { Obstetric condition } \\
\text { category* }\end{array}$ & $\begin{array}{l}\text { Nulliparas } \\
(n=336)\end{array}$ & $\begin{array}{l}\text { Multiparas without } \\
\text { previous cesarean } \\
\text { delivery }(n=703)\end{array}$ & $\begin{array}{l}\text { Multiparas with } \\
\text { previous cesarean } \\
\text { delivery }(n=84)\end{array}$ & $\begin{array}{l}\text { Overall population } \\
(\mathrm{N}=1123)\end{array}$ \\
\hline Multiple pregnancy & 0 & $40.0 \%(2 / 5)$ & 0 & $40.0 \%(2 / 5)$ \\
\hline $\begin{array}{l}\text { Breech/transverse lie } \\
\text { presentation }\end{array}$ & $75 \%(9 / 12)$ & $71.4 \%(10 / 14)$ & $83.3 \%(5 / 6)$ & $75.0 \%(25 / 32)$ \\
\hline Preterm birth ( < 36 wk) & $33.3 \%(2 / 6)$ & $13.3 \%(2 / 15)$ & $60 \%(3 / 5)$ & $26.9 \%(7 / 26)$ \\
\hline No trial of labor permitted ${ }^{\dagger}$ & $100 \%(1 / 1)$ & $100 \%(5 / 5)$ & $100 \%(8 / 8)$ & $100 \%(14 / 14)$ \\
\hline$\geq 36$ wk with medical risk & $12.5 \%(13 / 104)$ & $4.5 \%(7 / 155)$ & $16.6 \%(4 / 24)$ & $8.5 \%(24 / 283)$ \\
\hline$\geq 36$ wk without medical risk & $1.9 \%(4 / 213)$ & $0.6 \%(3 / 509)$ & $9.8 \%(4 / 41)$ & $1.4 \%(11 / 763)$ \\
\hline Total & $8.6 \%(29 / 336)$ & $4.1 \%(29 / 703)$ & $28.6 \%(24 / 84)$ & $7.3 \%(82 / 1123)$ \\
\hline
\end{tabular}

* Groups are mutually exclusive, with women categorized as belonging to the first group into which they fit.

+ Includes women with scheduled cesarean delivery for medical indication and those with indication at admission to labor and delivery that precludes a trial of labor. For multiparas with previous cesarean delivery, also includes women with 2 or more previous cesarean deliveries and women with a previous classical cesarean scar.

\section{Table 4. Adjusted Zuni-Ramah Cesarean Delivery Rate by Case-Mix Analysis

\begin{tabular}{|c|c|c|c|}
\hline tion & $\begin{array}{l}\text { Crude cesarean } \\
\text { delivery rate }\end{array}$ & $\begin{array}{l}\text { Adjusted* cesarean } \\
\text { delivery rate }(95 \% \mathrm{Cl})\end{array}$ & $\begin{array}{c}\text { Adjusted rate } \\
\text { difference }(95 \% \mathrm{Cl})\end{array}$ \\
\hline andardiza & $21.5 \%$ & 21. & NA \\
\hline uni- & $7.3 \%$ & $11.5 \%(9.9 \%-13.1 \%)$ & $=10.0 \%(-12.0 \%$ to -8.1 \\
\hline
\end{tabular}

$\mathrm{Cl}$ indicates confidence interval; NA, not applicable.

* Adjusted to the case mix of the published data for the Boston community-based practitioners. ${ }^{26}$

+ A community-based obstetric population in Boston.

$\neq \mathrm{P}<.0001$.

in settings in which women must be transferred for cesarean delivery is the potential for adverse neonatal or maternal outcome associated with deferred surgery. The Healthy People goals have been questioned as encouraging obstetrical practices such as increased operative vaginal delivery and TOLAC that may result in increased neonatal morbidity and mortality, as well as increased maternal morbidity from uterine rupture. ${ }^{7}$

An earlier study demonstrated that perinatal mortality and neonatal resuscitation rates in the ZuniRamah population are similar to nationwide rates. ${ }^{24}$ The perinatal mortality rate of $11.4 / 1000$ births (95\% CI, 5.1-17.8 by Poisson distribution) was comparable with the 1991 nationwide rate of 12.8 .

The study also included a case-by-case review of all cesarean deliveries for fetal distress at referral hospitals, obstetrical emergencies at Zuni-Ramah Hospital, and infants with low Apgar scores. The review showed no evidence of adverse outcomes caused by deferred cesarean deliveries. There were no cases of uterine rupture in the study population.

The case-mix analysis (Tables 3 and 4) and standard primipara analysis are unable to standardize for cultural and genetic variables. These are important variables in our population, which was $66.9 \%$ Zuni and $30.8 \%$ Navajo. The demographics and obstetrical outcomes of Zuni-Ramah women are compared with all Native American women in New Mexico in 1994 (Table 2) to provide a culturally and genetically similar, but not identical, comparison group. Although the cesarean delivery rate for all Native American women in New Mexico was only $12 \%$ in $1994,{ }^{36}$ this was significantly higher than the rate for Zuni-Ramah women. The age, parity, and gestational age distribution are similar between Zuni-Ramah women and the New Mexico Native American obstetrical population.

\section{DISCUSSION}

The cesarean delivery rate of $7.3 \%$ is approximately one third of the national rate, primarily because of the decreased relative risk of cesarean delivery for labor dystocia (0.24, 95\% CI, 0.16-0.36) and elective repeat cesarean delivery $(0.11,95 \% \mathrm{CI}, 0.05-0.25)$. The casemix standardization and standard primipara analysis demonstrate that the low rate is not attributable to an obstetrical population at lower risk. The Zuni-Ramah population has a high incidence of diabetes and preeclampsia; the cesarean delivery rates are, however, dramatically lower than national rates for women with these medical complications. Because the cesarean delivery rate of the study participants was significantly lower than the $12 \%$ rate for all Native American women in New Mexico, factors other than ethnicity and geographic location may play a role.

Potential factors include perinatal system design and obstetrical management, the genetic and geographic variables particular to the Zuni-Ramah community, 
Table 5. Indications for Cesarean Delivery in the Zuni-Ramah and Nationwide US Populations

\begin{tabular}{|c|c|c|c|c|c|}
\hline Indication & $\begin{array}{c}\text { Number of } \\
\text { cesarean } \\
\text { deliveries, } \\
\text { Zuni-Ramah }\end{array}$ & $\begin{array}{l}\% \text { of cesarean } \\
\text { deliveries }\end{array}$ & $\begin{array}{l}\% \text { of total births, } \\
\text { Zuni-Ramah* }\end{array}$ & $\begin{array}{c}\% \text { of total births, } \\
\text { nationwide }\end{array}$ & $\begin{array}{c}\text { Relative risk of } \\
\text { cesarean delivery } \\
\text { for each indication } \\
(95 \% \mathrm{Cl})\end{array}$ \\
\hline \multicolumn{6}{|l|}{$\begin{array}{l}\text { Total cesarean } \\
\text { deliveries }\end{array}$} \\
\hline Dystocia & 24 & 28.9 & 2.1 & 8.87 & $0.24(0.16-0.36)$ \\
\hline Breech & 22 & 26.6 & 1.9 & 2.95 & $0.44(0.66-1.00)$ \\
\hline Fetal distress & 12 & 14.5 & 1.1 & 2.16 & $0.49(0.28-0.86)$ \\
\hline Elective repeat & 6 & 7.2 & 0.5 & 4.66 & $0.11(0.05-0.25)$ \\
\hline Other & 19 & 22.9 & 1.7 & 3.39 & $0.50(0.32-0.77)$ \\
\hline Total & 83 & 100 & 7.30 & 22.03 & $0.27(0.33-0.41)$ \\
\hline \multicolumn{6}{|l|}{$\begin{array}{l}\text { Primary cesarean } \\
\text { deliveries }^{\dagger}\end{array}$} \\
\hline Dystocia & 19 & 32.8 & 1.81 & 8.12 & $0.22(0.14-0.35)$ \\
\hline Breech & 18 & 31.0 & 1.72 & 2.94 & $0.59(0.37-0.93)$ \\
\hline Fetal distress & 8 & 13.8 & 0.77 & 2.02 & $0.38(0.19-0.76)$ \\
\hline Other & 13 & 22.4 & 1.24 & 2.72 & $0.46(0.27-0.79)$ \\
\hline Total & 58 & 100 & 5.55 & 15.8 & $0.35(0.27-0.45)$ \\
\hline
\end{tabular}

and cultural attitudes toward childbirth. Because of the need to transport patients for cesarean delivery, at least 2 physicians had to concur that intervention (ie, transfer and cesarean delivery) was required. This mandatory consultation may decrease the rate of nonemergent cesarean deliveries for the indications of dystocia and nonreassuring fetal heart tones. The patients' desire to avoid transfer often leads to a mobilization of social support (including family members, religious leaders, and traditional healers) that may provide the encouragement to continue a difficult labor. Social support during labor has been demonstrated to lower the incidence of cesarean delivery. ${ }^{37,38}$

The low rate of cesarean deliveries may be influenced by the predominant involvement of family physicians and nurse-midwives. Family physicians attended more than $95 \%$ of the deliveries at Zuni Indian Hospital, and nurse-midwives were present at $47 \%$ of the vaginal deliveries at GIMC. Family physicians have a significantly lower rate of cesarean deliveries and other obstetrical interventions than obstetrician-gynecologists. ${ }^{39-41}$ Several retrospective studies have demonstrated a lower rate of cesarean deliveries with nurse-midwife care than with physician management, ${ }^{42-44}$ although randomized studies have not consistently demonstrated this. ${ }^{45-47}$

Forty-six percent of the difference between ZuniRamah and national cesarean rates was attributable to decreased use of cesarean delivery for dystocia. During the study, it was common for physicians nationwide to perform cesarean deliveries for dystocia when a woman in active labor failed to make progress in dilation and/or fetal descent despite more than 2 hours of adequate contractions. At Zuni-Ramah Hospital and GIMC, it was common to allow more time before intervening with transfer or cesarean delivery. A 1999 study validated this approach by demonstrating that continuing oxytocin augmentation for at least 4 hours, despite failure of labor progress after 2 hours of adequate contractions, resulted in $62 \%$ of these women achieving a vaginal delivery. ${ }^{48}$ In addition, recent studies demonstrate a broader range in the length of active labor than the definitions of protracted labor defined by Friedman's cohort in the 1950s. ${ }^{49-51}$

Lower birth weights may explain part of the lower incidence of cesarean deliveries; only $4.8 \%$ of ZuniRamah birth weights were greater than 4000 g, compared with $9.3 \%$ of those among all Native American women in New Mexico (Table 2). The average weight of live births was $3232 \mathrm{~g}$ in the Zuni-Ramah population, which was $118 \mathrm{~g}$ less than the average 1996 US birth weight. ${ }^{28}$ However, even among Zuni-Ramah women with babies weighing more than $4000 \mathrm{~g}$, the cesarean delivery rate was only $9.2 \%$. The decrease in birth weight may be related to the altitude, which is 6000 to 7000 feet above sea level, or the genetic composition of the population. The maternal population in the study was more than $97 \%$ Zuni and Navajo with minimal intermarriage between the tribes or with other ethnic groups. Genetic homogeneity may result in a decreased incidence of cephalopelvic disproportion. Ethnicity has been shown to influence cesarean deliv- 
ery rates in studies of the Hmong population in California and the Maori people in New Zealand; these ethnic groups had cesarean delivery rates of $6.5 \%$ and $3.9 \%$, respectively. ${ }^{22,23}$

Cultural attitudes toward childbirth are a third potential factor in the lower cesarean rate. The Zuni culture may be described as pronatalist in that fertility is a common theme of religious activities. The ability to give birth with minimal obstetrical intervention appears to be a cultural norm based on the reluctance of women to use obstetrical interventions, such as labor analgesia. Several female family members usually accompany a Zuni woman in labor. These labor companions may function in a role similar to doulas. Fear of childbirth has been shown to be a risk factor for cesarean delivery and the pronatalist culture may diminish fear. ${ }^{52}$ The cultural attitudes toward birth likely explain the decision of $93 \%$ of women with a previous cesarean delivery to have a trial of labor.

The cesarean delivery rate in the Zuni-Ramah community is much lower than that of the comparison populations of all Native American women in New Mexico and the total US population because of a dramatically lower incidence of cesarean delivery for dystocia and a higher rate of vaginal birth after cesarean delivery. The low rate of cesarean delivery cannot be explained by demographics or obstetrical risk factors, as demonstrated by the case-mix analysis. The low rate of cesarean delivery likely results from a complex interaction of the perinatal system, cultural attitudes toward childbirth, and genetics. A study analyzing the cesarean delivery rates of Zuni and Navajo women who live in urban communities and are cared for in other perinatal systems would facilitate determination of the relative importance of these factors. The low cesarean delivery rates in women with diabetes or preeclampsia suggest that the high rates of cesarean delivery for women noted in other studies may be preventable. Family physicians may be able to reduce the cesarean delivery rates in their obstetrical units by adopting some of the practices from the Zuni-Ramah population, including avoiding unneeded inductions, not routinely intervening with cesarean delivery for labor dystocia until after at least 4 hours of adequate contractions, ensuring adequate provision of continuous labor support, and facilitating consultation before nonemergent cesarean delivery.

To read commentaries or to post a response to this article, see the online version at http://www.annfammed.org/cgi/content/full/1/1/36.

Key words: Cesarean section, Maternal health services, Obstetrics, Pregnancy outcomes, Pregnancy, Childbirth, Puerperium

Received October 7, 2002; accepted January 12, 2003.

\section{Acknowledgments}

The authors thank Robert Rhyne, MD, for editorial assistance in manuscript preparation and Betty Skipper, $\mathrm{PhD}$, for statistical assistance.

The current Zuni-Ramah maternity care practice guidelines for prenatal care, antepartum transfer and intrapartum care are available at http://hsc.unm.edu/ $\mathrm{fcm} /$ research/zuni.

\section{References}

1. Menard MK. Cesarean delivery rates in the United States. The 1990s. Obstet Gynecol Clin North Am 1999;26:275-286.

2. Menacker $F$, Curtin SC. Trends in cesarean birth and vaginal birth after previous cesarean, 1991-99. Natl Vital Stat Rep 2001;49:1-16.

3. Martin JA, Park MM, Sutton PD. Births: preliminary data for 2001 Natl Vital Stat Rep 2002;50:1-20.

4. O'Driscoll K, Foley M. Correlation of decrease in perinatal mortality and increase in cesarean section rates. Obstet Gynecol 1983;61:1-5.

5. Notzon FC. International differences in the use of obstetric interventions. JAMA 1990;263:3286-3291.

6. US Public Health Service. Healthy people 2000: a national health promotion and disease prevention objectives: full report, with commentary. Washington, DC: US Dept of Health and Human Services, Public Health Service; 1990:378. DHHS publication no. 91-50212.

7. Sachs BP, Kobelin C, Castro MA, Frigoletto F. The risks of lowering the cesarean-delivery rate. N Engl J Med 1999;340:54-57.

8. US Dept of Health and Human Services. Healthy people 2010: understanding and improving health. 2nd ed. Washington, DC: US Dept of Health and Human Services, 2000:16-30.

9. Leveno KJ, Cunningham FG, Nelson S, et al. A prospective comparison of selective and universal electronic fetal monitoring in 34,995 pregnancies. N Engl J Med 1986;315:615-619.

10. Thacker SB, Stroup DF, Peterson HB. Efficacy and safety of intrapartum electronic fetal monitoring: an update. Obstet Gynecol 1995; 86(4 Pt 1):613-620.

11. Flamm BL, Berwick DM, Kabcenell A. Reducing cesarean section rates safely: lessons from a "breakthrough series" collaborative. Birth 1998;25:117-124.

12. Localio AR, Lawthers AG, Bengtson JM, et al. Relationship between malpractice claims and cesarean delivery. JAMA 1993;269:366-373.

13. Tussing AD, Wojtowycz MA. Malpractice, defensive medicine, and obstetric behavior. Med Care 1997;35:172-191.

14. Yawn BP, Wollan P, McKeon K, Field CS. Temporal changes in rates and reasons for medical induction of term labor, 1980-1996. Am J Obstet Gynecol 2001;184:611-619.

15. Hankins GD, Rowe TF. Operative vaginal delivery-year 2000. Am J Obstet Gynecol 1996;175:275-282.

16. Hannah ME, Hannah WJ, Hewson SA, Hodnett ED, Saigal S, Willan AR. Planned caesarean section versus planned vaginal birth for breech presentation at term: a randomised multicentre trial. Term Breech Trial Collaborative Group. Lancet 2000;356:1375-1383.

17. Cnattingius R, Cnattingius S, Notzon FC. Obstacles to reducing cesarean rates in a low-cesarean setting: the effect of maternal age, height, and weight. Obstet Gynecol 1998;92(4 Pt 1):501-506.

18. Parrish KM, Holt VL, Easterling TR, Connell FA, LoGerfo JP. Effect of changes in maternal age, parity, and birth weight distribution on primary cesarean delivery rates. JAMA 1994;271:443-447.

19. Ecker JL, Chen KT, Cohen AP, Riley LE, Lieberman ES. Increased risk of cesarean delivery with advancing maternal age: indications and 
associated factors in nulliparous women. Am J Obstet Gynecol 2001; 185:883-887.

20. Peipert JF, Bracken MB. Maternal age: an independent risk factor for cesarean delivery. Obstet Gynecol 1993;81:200-205.

21. Gould JB, Davey B, Stafford RS. Socioeconomic differences in rates of cesarean section. N Engl J Med 1989;321:233-239.

22. Helsel D, Petitti DB, Kunstadter P. Pregnancy among the Hmong: birthweight, age, and parity. Am J Public Health 1992;82:1361-1364.

23. Johnson NP, Lewis J, Ansell DA. Does ethnicity influence obstetric intervention? N Z Med J 1995;108:511-512.

24. Leeman L, Leeman R. Do all hospitals need cesarean delivery capability? An outcomes study of maternity care in a rural hospital without on-site cesarean capability. J Fam Pract 2002;51:129-134.

25. National Diabetes Data Group. Classification and diagnosis of diabetes mellitus and other categories of glucose intolerance. Diabetes 1979;28:1039-1057.

26. Lieberman E, Lang JM, Heffner LJ, Cohen A. Assessing the role of case mix in cesarean delivery rates. Obstet Gynecol 1998;92:1-7.

27. American College of Obstetricians and Gynecologists, Task Force on Cesarean Delivery Rates. Evaluation of cesarean delivery. Washington, DC: American College of Obstetricians and Gynecologists, 2000.

28. Ventura SJ, Martin JA, Curtin SC, Mathews TJ. Report of final natality statistics, 1996. Mon Vital Stat Rep 1998;46(11 Suppl):1-99.

29. Gregory KD, Curtin SC, Taffel SM, Notzon FC. Changes in indications for cesarean delivery: United States, 1985 and 1994. Am J Public Health 1998;88:1384-1387.

30. Cowan RK, Kinch RA, Ellis B, Anderson R. Trial of labor following cesarean delivery. Obstet Gynecol 1994;83:933-936.

31. Flamm BL, Newman LA, Thomas SJ, Fallon D, Yoshida MM. Vaginal birth after cesarean delivery: results of a 5-year multicenter collaborative study. Obstet Gynecol 1990;76(5 Pt 1):750-754.

32. Roberts RG, Bell HS, Wall EM, Moy JG, Hess GH, Bower HP. Trial of labor or repeated cesarean section. Arch Fam Med 1997;6:120-125.

33. Hypertension in Pregnancy. Washington DC: American College of Obstetricians and Gynecologists; 1996. ACOG Technical Bulletin \#219.

34. Cleary R, Beard RW, Chapple J, et al. The standard primipara as a basis for inter-unit comparisons of maternity care. Br J Obstet Gynaecol 1996;103:223-229.

35. Main EK. Reducing cesarean birth rates with data-driven quality improvement activities. Pediatrics 1999;103(1 Suppl E):374-383.

36. Schiff M, Rogers C. Factors predicting cesarean delivery for American Indian women in New Mexico. Birth 1999;26:226-231.
37. Kennell J, Klaus M, McGrath S, Robertson S, Hinkley C. Continuous emotional support during labor in a US hospital. A randomized controlled trial. JAMA 1991;265:2197-2201.

38. Scott KD, Berkowitz GB, Klaus M. A comparison of intermittent and continuous support during labor: a meta-analysis. Am J Obstet Gynecol 1999;180:1054-1059.

39. Deutchman ME, Sills D, Connor PD. Perinatal outcomes: a comparison between family physicians and obstetricians. J Am Board Fam Pract 1995;8:440-447.

40. Hueston WJ, Applegate JA, Mansfield CJ, King DE, McClaflin RR. Practice variations between family physicians and obstetricians in the management of low-risk pregnancies. J Fam Pract 1995;40:345-351.

41. MacDonald SE, Voaklander K, Birtwhistle RV. A comparison of family physicians' and obstetricians' intrapartum management of low-risk pregnancies. J Fam Pract 1993;37:457-462.

42. Davis LG, Riedmann GL, Sapiro M, Minogue JP, Kazer RR. Cesarean section rates in low-risk private patients managed by certified nursemidwives and obstetricians. J Nurse Midwifery 1994;39:91-97.

43. Oakley D, Murtland T, Mayes F, et al. Processes of care. Comparisons of certified nurse-midwives and obstetricians. J Nurse Midwifery 1995;40:399-409.

44. Butler J, Abrams B, Parker J, Roberts JM, Laros RK Jr. Supportive nurse-midwife care is associated with a reduced incidence of cesarean section. Am J Obstet Gynecol 1993;168:1407-1413.

45. Harvey S, Jarrell J, Brant R, Stainton C, Rach D. A randomized, controlled trial of nurse-midwifery care. Birth 1996;23:128-135.

46. Turnbull D, Holmes A, Shields N, et al. Randomised, controlled trial of efficacy of midwife-managed care. Lancet 1996;348:213-218.

47. Chambliss LR, Daly C, Medearis AL, Ames M, Kayne M, Paul R. The role of selection bias in comparing cesarean birth rates between physician and midwifery management. Obstet Gynecol 1992;80:161-165.

48. Rouse DJ, Owen J, Hauth JC. Active-phase labor arrest: oxytocin augmentation for at least 4 hours. Obstet Gynecol 1999;93:323-328.

49. Albers LL, Schiff M, Gorwoda JG. The length of active labor in normal pregnancies. Obstet Gynecol 1996;87:355-359.

50. Zhang J, Troendle JF, Yancey MK. Reassessing the labor curve in nulliparous women. Am J Obstet Gynecol 2002;187:824-828.

51. Friedman EA. Primigravid labor: A graphicostatistical analysis. Obstet Gynecol 1955;6:567-589

52. Ryding EL, Wijma B, Wijma K, Rydhstrom H. Fear of childbirth during pregnancy may increase the risk of emergency cesarean section. Acta Obstet Gynecol Scand 1998;77:542-547. 